\title{
RISIKO KELUHAN SINDROM TEROWONGAN KARPAL(STK) PADA KARYAWAN WANITA PENGUPAS KEPITING DI PT. X SULAWESI SELATAN
}

\author{
Fatmawaty Mallapianga ${ }^{*}$, Azrifula, Rini Jusriania, Indriani Lestaluhua \\ a Department of Public Health, Faculty Of Medicine And Health Sciences, Universitas \\ Islam Negeri Alauddin, Makassar 92113, Indonesia \\ *Corresponding author. \\ E-mail Address: fatmawaty.mallapiang@uin-alauddin.ac.id (F. Mallapiang)
}

\begin{abstract}
Abstrak
Penelitian ini bertujuan untuk mengetahui risiko keluhan Sindrom Terowongan Karpal (STK) berdasarkan umur, masa kerja, lama kerja, pengulangan gerakan, dan bekerja dengan menggengam pada karyawan wanita pengupas kepiting di PT. X. Jenis penelitian ini adalah penelitian kuantitatif dengan pendekatan deskriptif observasional pada sampel sebesar 80 responden (total sampling). Berdasarkan hasil penelitian diperoleh 92,5 \% (74 orang) responden mengalami keluhan Sindrom Terowongan Karpal, 58,75\% responden yang berumur $\geq 35$ tahun mengalami keluhan STK, 56,25\%, responden dengan masa kerja $\geq 2$ tahun mengalami keluhan STK, 90\% responden dengan lama kerja $\geq 6$ jam/hari mengalami STK, responden dengan gerakan berulang $\geq 30$ gerakan/menit mengalami keluhan STK sebesar 82,50\%, dan responden dengan pekerjaan menggenggam $\geq 6$ jam /hari mengalami STK sebesar 71,25\%. Diharapkan pihak PT.X memaksimalkan sosialisasi pencegahan STK kepada karyawan wanita melalui pemberdayaan teman sebaya.
\end{abstract}

Kata Kunci : Sindrom Terowongan Karpal(STK); Karyawan wanita; Pengupas kepiting

\section{PENDAHULUAN}

Sindrom Terowongan Karpal merupakan satu diantara Keluhan Muskuloskeletal terkait pekerjaan yang menyebabkan nyeri, mati rasa, dan kesemutan pada tangan dan lengan (Genova, Dix, Saefan, Thakur, \& Hassan, 2020) yang didefinisikan oleh kompresi saraf median di pergelangan tangan dengan penyebab tersering adalah idiopatik (Chammas et al., 2014; Ghasemi-Rad et al., 2014).

Pekerjaan yang dilakukan dengan gerakan berulang pada tangan atau jari tangan secara terus menerus, terjadi kontraksi kuat pada tendon, gerakan pergelangan tangan menekuk ke bawah dan ke atas, serta pekerjaan menggenggam 
atau menjepit dapat memengaruhi terjadinya Sindrom Terowongan Karpal (Ghasemi-Rad et al., 2014; K. M. Musolin \& Ramsey, 2017; Palmer, 2011; Spahn, Wollny, Hartmann, Schiele, \& Hofmann, 2012). Hal ini terjadi akibat saraf medianus pada pergelangan tangan tejepit oleh pembungkus tendon fleksor yang menebal, tulang terikat, dan edema/massa jaringan lunak (Ghasemi, Gholamizadeh, Rahmani, \& Doosti-Irani, 2020; K. M. Musolin \& Ramsey, 2017).

Prevalensi STK sebanyak 7,8\% dari 4321 pekerja industri dengan proporsi lebih tinggi pada perempuan dan kategori usia yang lebih tua. Insiden STK yang diamati di antara 5,8\% dari 3515 pekerja menghasilkan tingkat insiden 2,3 per 100 orang per tahun. Prevalensi munculnya gejala sebesar 15,2\% (Dale et al., 2013). Selain itu, penelitian yang dilaporkan oleh (K. M. Musolin \& Ramsey, 2017) memaparkan bahwa pekerja yang mengandalkan gerakan dan kekuatan tangan pada pengolahan unggas sangat berisiko terkena STK. Sebanyak 81\% pekerjaan melampui ambang batas yang ditetapkan oleh American Conference of Governmental Industrial Hygienists (ACGIH). Pada penelitian lainnya dilaporkan, bahwa pekerja di pabrik unggas juga menemukan hasil yang sebanding (42\% pekerja dengan STK) berdasarkan definisi kasus yang sama meliputi gejala pada tangan, dan pengukuran konduksi saraf objektif (K. Musolin, Ramsey, Wassell, \& Hard, 2014; NIOSH, 2014).

Sebanyak 27.157 orang dewasa dengan 17.524 merupakan pekerja didiagnosis akan mengalami STK seumur hidup dengan prevalensi 6,7\%. Prevalensi 12 bulan sebesar 3,1\%, mewakili sekitar 4,8 juta pekerja dengan STK. Sindrom ini memengaruhi hampir 5 juta pekerja A.S. pada tahun 2010, dengan prevalensi yang bervariasi menurut karakteristik demografis (Luckhaupt et al., 2013). Sebesar 67\% karyawan wanita dengan jenis pekerjaan yang kasar dan membutuhkan kekuatan diketahui memiliki relative rate (RR) sebesar 3,0. Insiden kejadiannya lebih tinggi pada penduduk yang bekerja dibandingkan dengan yang tidak bekerja (Roquelaure et al., 2008).

Prevalensi gangguan STK pada populasi umum di Belanda adalah 0,6\% untuk pria dan 5,8\% untuk wanita. Bahkan sekitar 2,7\% dari populasi memiliki STK yang terdokumentasi secara klinis dan elektrofisiologis. Berdasarkan jenis 
kelamin, wanita jauh lebih rentan terhadap gangguan STK yakni dalam rasio 3: 1 bahkan bisa menjadi sekitar 10: 1 (Yazdanpanah et al., 2012).

Berdasarkan penelitian F.Mallapiang dan Wahyudi (2015) bahwa terdapat $35 \%$ pekerja batu tatakan dengan gerakan berulang mengalami Carpal Tunnel Syndrome (CTS), 38\% pekerja yang melakukan pekerjaan menggenggam atau menjepit mengalami CTS, dan 38\% pekerja dengan postur janggal mengalami CTS.

Karwayan wanita PT. X melakukan pekerjaan pengupasan kepiting dari cangkangnya sehingga menghasilkan daging siap olah. Pekerjaan ini membutuhkan gerakan tangan yang cepat dan cekatan. Selain itu pengupasan kepiting mengharuskan karyawan wanita melakukan gerakan berulang dan mengenggam secara terus menerus dalam waktu yang lama, sehingga berisiko mengalami Keluhan Sindrom Terowongan Karpal.

Tenaga kerja wanita merupakan salah satu yang paling rentan terkena STK (Roquelaure et al., 2008). Karyawan wanita dalam berbagai jenis pekerjaan telah dilaporkan rentan terkena STK. Devrimsel, Kirbas, Yildirim, Turkyilmaz, and Sahin (2014) melaporkan bahwa karyawan wanita pada pertanian teh, bekerja dengan fleksi dan ekstensi berulang pada pergelangan tangan sangat meningkatkan risiko STK. Newington, Harris, and Walker-Bone (2015) melaporkan bahwa hasil dari hampir semua penelitian diperoleh bahwa Sindrom Terowongan Karpal frekuensi kejadiannya lebih besar pada wanita, dengan insiden tahunan sebesar 1,5 per 1000 dibandingkan dengan 0,5 per 1000 pada pria. Perbedaan jenis kelamin dapat dijelaskan setidaknya sebagian oleh faktor hormonal karena wanita hamil dan menyusui memiliki peningkatan risiko Sindrom Terowongan Karpal, serta yang berada di tahun menopause pertama, meminum pil kontrasepsi oral atau menggunakan terapi penggantian hormon juga menjadi faktor dalam meningkatnya kejadian STK pada karyawan wanita.

Pelibatan Karyawan wanita dalam sektor industri dimaksudkan untuk membantu perekonomian keluarga sehingga karyawan wanita menjalankan peran ganda, yaitu membantu suami mencari nafkah untuk memenuhi kebutuhan ekonomi keluarga, disisi lain pekerjaan mengasuh dan mendidik anak masih dibebankan kepadanya seorang diri (Sosan, 2013; Triana \& Krisnani, 2018; Yazdanpanah et al., 2012). 
Berdasarkan hasil observasi yang dilakukan peneliti pada 12 karyawan wanita pengupas kepiting di PT.X diperoleh 10 orang karyawan (83,3\%) mengalami keluhan kram, nyeri pada tangan seperti terkena aliran listrik dan mati rasa, serta jari tangan sulit mengepal. Oleh karena itu, peneliti merasa penting untuk melakukan penelitian terkait "Risiko Keluhan Sindrom Terowongan Karpal Pada Karyawan wanita Pengupas Kepiting di PT. X, Propinsi Sulawesi Selatan.

\section{METODE PENELITIAN}

Penelitian ini adalah penelitian Kuantitatif dengan pendekatan deskriptif observasional pada 80 karyawan wanita pengupas kepiting di PT.X. Tujuan penelitian ini adalah untuk mengetahui keluhan Sindrom Terowongan Karpal berdasarkan umur, masa kerja, lama kerja, dan gerakan berulang.

Dalam pengumpulan data penelitian ini menggunakan Instrumen berupa kuesioner yang yang memuat pertanyaan terkait variabel-variabel yang diteliti. Kemudian data yang diperoleh diolah menggunakan SPSS untuk memberikan analisis deskriptif terkait keluhan STK pada responden berdasarkan umur, masa kerja, lama kerja, gerakan berulang dan pekerjaan menggenggam.

\section{HASIL PENELITIAN}

Berikut ini hasil penelitian pada karyawan wanita pengupas kepiting di PT.X:

Tabel 1. Distribusi Responden Menurut Umur, Masa Kerja, Lama Kerja, Gerakan Berulang dan Pekerjaan Menggenggam

\begin{tabular}{|c|c|c|c|}
\hline \multicolumn{2}{|c|}{ Variabel } & n (80) & $\%$ \\
\hline $\begin{array}{cc}\text { Umur (tahun) } \\
\qquad \quad 18-34 \\
-\quad 35-51\end{array}$ & $\begin{array}{ll}\text { Kategori } \\
\text { - } & \text { Tidak } \\
\text { berisiko } \\
\text { - } & \text { Berisiko }\end{array}$ & $\begin{array}{l}31 \\
49\end{array}$ & $\begin{array}{l}38,75 \\
61,25\end{array}$ \\
\hline $\begin{array}{c}\text { Masa Kerja (tahun) } \\
-\quad<2 \\
-\quad 2-4\end{array}$ & $\begin{array}{ll}\text { - } & \text { Tidak } \\
\text { berisiko } \\
\text { - } & \text { Berisiko } \\
\end{array}$ & $\begin{array}{l}34 \\
46\end{array}$ & $\begin{array}{l}42,50 \\
57,70\end{array}$ \\
\hline $\begin{array}{c}\text { Lama Kerja (jam) } \\
\bullet<6\end{array}$ & - $\quad$ Tidak & 22 & 27,50 \\
\hline
\end{tabular}




\begin{tabular}{|c|c|c|c|}
\hline - $\geq 6$ & $\begin{array}{ll} & \text { berisiko } \\
\text { - } & \text { Berisiko }\end{array}$ & 58 & 72,50 \\
\hline $\begin{aligned} & \text { Gerakan Berulang } \\
& \text { - } 15 \\
& \text { kali/menit } \\
& \text { - } 30 \\
& \text { kali/menit }\end{aligned}$ & $\begin{array}{ll}\text { - } & \text { Tidak } \\
\text { berisiko } \\
\text { - } & \text { Berisiko }\end{array}$ & $\begin{array}{l}10 \\
70\end{array}$ & $\begin{array}{l}12,50 \\
87,50\end{array}$ \\
\hline $\begin{array}{l}\text { Pekerjaan } \\
\text { menggenggam } \\
\bullet \quad<6 \text { jam/8 } \\
\quad \text { jam } \\
\bullet \quad \geq 6 \text { jam/8 } \\
\quad \text { jam }\end{array}$ & $\begin{array}{ll}\text { - } & \text { Tidak } \\
\text { berisiko } \\
\text { - } & \text { Berisiko }\end{array}$ & $\begin{array}{l}22 \\
58\end{array}$ & $\begin{array}{l}17,60 \\
46,40\end{array}$ \\
\hline
\end{tabular}

Sumber : Data Primer

Berdasarkan tabel 1 menunjukkan mayoritas responden berada pada kategori umur berisiko yaitu umur 35-51 tahun sebesar 49 responden (61,25\%), masa kerja kategori berisiko yaitu 2- 4 tahun sebesar 46 responden(57,70\%) dan lama kerja kategori berisiko bila $\geq 6$ jam sebesar 58 responden atau 72,50\%. Responden mayoritas melakukan gerakan berulang 30 kali permenit sebesar 87,50\% dan melakukan pekerjaan menggenggam selama $\geq 6$ jam/8 jam sebesar 46,40\%.

Tabel 2. Distribusi Responden Menurut Keluhan Sindrom Terowongan Karpal di PT. X Prov.Sulawesi Selatan

\begin{tabular}{lcc}
\hline $\begin{array}{l}\text { Keluhan Sindrom Terowongan } \\
\text { Karpal }\end{array}$ & n (156) & \% \\
\hline Kram atau Kesemutan & 71 & 88,8 \\
\hline Gemetar & 20 & 25,0 \\
\hline Mati Rasa & 18 & 22,5 \\
\hline Nyeri & 34 & 42,5 \\
\hline Sulit mengepal & 13 & 16,3 \\
\hline
\end{tabular}

Sumber : Data Primer

Berdasarkan Tabel 2 terlihat bahwa beberapa responden mengalami keluhan STK lebih dari 2 keluhan, dan keluhan STK terbanyak yang dialami responden adalah kram atau kesemutan pada bagian tangan sebesar 71 responden $(88,8 \%)$, dan nyeri 34 responden $(42,5 \%)$. 
Tabel 3. Distribusi Keluhan Sindrom Terowongan Karpal (STK)

Menurut Variabel Independen

\begin{tabular}{|c|c|c|c|c|c|c|}
\hline \multirow{3}{*}{ Variabel Independen } & \multicolumn{4}{|c|}{$\begin{array}{c}\text { Keluhan Sindrom Terowongan } \\
\text { Karpal (STK) }\end{array}$} & \multicolumn{2}{|c|}{ Jumlah } \\
\hline & \multicolumn{2}{|c|}{ Ada Keluhan } & \multicolumn{2}{|c|}{$\begin{array}{c}\text { Tidak ada } \\
\text { Koluhan }\end{array}$} & \multirow[t]{2}{*}{$\mathrm{n}$} & \multirow[t]{2}{*}{$\%$} \\
\hline & $\mathrm{n}$ & $\%$ & $\mathrm{n}$ & \% & & \\
\hline \begin{tabular}{ll}
\multicolumn{2}{|l}{ Umur } \\
\\
$\qquad \quad$ Tidak Berisiko \\
-
\end{tabular} & $\begin{array}{l}27 \\
47\end{array}$ & $\begin{array}{l}33,75 \\
58,75\end{array}$ & $\begin{array}{l}4 \\
2\end{array}$ & $\begin{array}{l}5,0 \\
2,5\end{array}$ & $\begin{array}{l}31 \\
49\end{array}$ & $\begin{array}{l}38,75 \\
61,25\end{array}$ \\
\hline $\begin{array}{cl}\text { Masa } & \text { Kerja } \\
\text { - } & \text { Tidak Berisiko } \\
\text { - } & \text { Berisiko }\end{array}$ & $\begin{array}{l}29 \\
45\end{array}$ & $\begin{array}{l}36,25 \\
56,25\end{array}$ & $\begin{array}{l}5 \\
1\end{array}$ & $\begin{array}{l}6,25 \\
1,25\end{array}$ & $\begin{array}{l}34 \\
46\end{array}$ & $\begin{array}{l}42,5 \\
57,5\end{array}$ \\
\hline $\begin{aligned} & \text { Lama Kerja } \\
& \text { - } \text { Tidak Berisiko } \\
& \text { - } \text { Berisiko }\end{aligned}$ & $\begin{array}{c}2 \\
72\end{array}$ & $\begin{array}{r}2,5 \\
90,0\end{array}$ & $\begin{array}{l}2 \\
4\end{array}$ & $\begin{array}{l}2,5 \\
5,0\end{array}$ & $\begin{array}{c}4 \\
76\end{array}$ & $\begin{array}{l}5 \\
95\end{array}$ \\
\hline $\begin{array}{cl}\text { Gerakan Berulang } \\
\text { - } & \text { Tidak Berisiko } \\
\text { - } & \text { Berisiko }\end{array}$ & $\begin{array}{c}8 \\
66\end{array}$ & $\begin{array}{l}10,0 \\
82,5\end{array}$ & $\begin{array}{l}2 \\
4\end{array}$ & $\begin{array}{l}2,5 \\
5,0\end{array}$ & $\begin{array}{l}10 \\
70\end{array}$ & $\begin{array}{l}12,5 \\
87,5\end{array}$ \\
\hline $\begin{array}{l}\text { Pekerjaan } \\
\text { menggenggam } \\
\text { - Tidak Berisiko } \\
\text { - } \quad \text { Berisiko }\end{array}$ & $\begin{array}{l}17 \\
57\end{array}$ & $\begin{array}{l}21,25 \\
71,25\end{array}$ & $\begin{array}{l}5 \\
1\end{array}$ & $\begin{array}{l}6,25 \\
1,25\end{array}$ & $\begin{array}{l}22 \\
58\end{array}$ & $\begin{array}{l}27,5 \\
72,5\end{array}$ \\
\hline
\end{tabular}

Sumber : Data Primer

Berdasarkan Tabel 3 menunjukkan bahwa dari 49 responden yang memiliki umur berisiko terdapt 47 responden (58,75\%) mengalami keluhan STK, dari 46 responden yang memiliki masa kerja berisiko terdapat 45 responden $(56,25 \%)$ mengalami keluhan STK, dari 76 responden dengan lama kerja berisiko terdapat 72 responden (90\%) mengalami keluhan STK, dari 70 responden yang melakukan gerakan berulang berisiko terdapat 66 responden $(82,5 \%)$ mengalami keluhan STK dan dari 58 responden yang melakukan pekerjaan menggenggam terdapat 57 responden $(71,25 \%)$ mengalami keluhan STK. 


\section{PEMBAHASAN}

\section{Gambaran Keluhan Sindrom Terowongan Karpal pada Karyawan wanita}

Karyawan wanita di PT.X terbagi ke dalam dua bagian unit kerja yaitu unit I bekerja sebagai pengupas atau pemisah daging kepiting dari cangkangnya dengan bantuan pisau, dan unit II bekerja pada bagian pengepakan daging kepiting siap olah.

Hasil penelitian menunjukkan 92,5\% atau 74 responden mengalami keluhan Sindrom Terowongan Karpal, dimana keluhan kram atau kesemutan pada jari tangan dan pergelangan tangan merupakan gejala yang paling banyak dirasakan oleh responden yaitu sebesar 72 responden, dan yang paling rendah adalah sulit mengepal sebesar 13 responden. Keluhan ini dirasakan sebagai akibat responden melakukan pekerjaannya dengan gerakan berulang, pekerjaan menggenggam pisau dan melakukan pekerjaan berulang dengan postur tangan yang janggal secara terus menerus selama 5-8 jam perhari.

Pekerjaan memisahkan daging kepiting dari cangkangnya sehingga menjadi daging siap olah mengharuskan responden melakukan pekerjaannya dengan gerakan berulang yang monoton dalam jangka waktu yang lama setiap hari kerja. Selain itu responden dalam bekerja melakukan pekerjaan menggenggam alat bantu berupa pisau untuk memisahkan daging kepiting tersebut dari cangkangnya, dan postur kerja dari tangan yang menekuk ke atas dan ke bawah yang dilakukan secara tidak ergonomis. Kesemuanya ini berisiko menyebabkan terjepitnya saraf medianus pada pergelangan tangan sehingga terjadi penyempitan pada terowongan karpal. Sindrom ini dapat mengganggu mobilitas, kekuatan, kemampuan atau pengendalian motorik yang memengaruhi kinerja karyawan wanita. Keluhan ini dirasakan saat bekerja dan setelah selesai bekerja. Terkadang responden terbangun di malam hari karena merasakan nyeri pada bagia jari dan telapak tangan, dan terkadang kehilangan kemampuan untuk menggenggam (Basuki, Jenie, \& Fikri, 2015).

Berbagai aktivitas yang melibatkan tangan secara berulang kerap dikaitkan dengan Sindrom Terowongan Karpal (STK). STK ditentukan oleh kompresi saraf median di pergelangan tangan. Setyowati, Dwijayanti, and Sultan 
(2015) melaporkan bahwa karyawan wanita pengupas kulit bawang merupakan pekerjaan berisiko yang dapat dengan mudah terkena STK. Terdapat hubungan antara repetitive motions, durasi kerja, pekerjaan service dan kejadian STK (Setyowati et al., 2015).

\section{Risiko Keluhan Sindrom Terowongan Karpal Berdasarkan Umur}

Penelitian ini menunjukkan bahwa terdapat 47 responden(58,75\%) memiliki umur berisiko ( $\geq 35$ tahun) dan 27 responden terdapat 47 responden (58,75\%) mengalami keluhan Sindrom Terowongan Karpal (STK).

Umur menjadi salah satu faktor penyumbang dalam terjadinya STK pada pekerja 0.990 (95\% CI, 0.984-0.996 (Guan et al., 2018). Insiden STK pada wanita paruh baya secara signifikan lebih tinggi dibandingkan pada pria.(Burt et al., 2013; Guan et al., 2018; Mansfield, Thacker, \& Sandford, 2018)

Selain itu terdapat responden memiliki umur berisiko tetapi 2,5\% tidak mengalami STK, hal ini terjadi karena responden pernah merasakan nyeri atau sakit pada tangan namun diabaikan saja karena menganggap hal tersebut sebagai suatu hal yang biasa (Pratiwi et al., 2014). Selain itu responden juga selama jam kerja tidak melakukan gerakan berulang yang berisiko yaitu melakukan gerakan berulang $>30$ kali permenit.

Lain halnya karyawan wanita yang berumur tidak berisiko namun mengalami Sindrom Terowongan Karpal sebesar 33,75\%, hal ini terjadi karena responden memiliki beban fisik yang berat saat bekerja. Penelitian ini sesuai dengan riset yang dilakukan Setyowati et al. (2015) yang mengungkapkan bahwa Sindrom Terowongan Karpal yang terjadi pada usia lebih muda dari 40 tahun disebabkan karena bekerja dengan gerakan yang menimbulkan tekanan saat mengupas bawang.

\section{Risiko Keluhan Sindrom Terowongan Karpal Berdasarkan Masa Kerja}

Berdasarkan tabel 3 responden kategori masa kerja yang berisiko dan mengalami Sindrom Terowongan Karpal sebesar 56,25\%. Hal ini sejalan dengan penelitian yang dilaporkan oleh Mohammad (2019) bahwa masa kerja karyawan wanita dengan menggunakan layar sentuh berpengaruh terhadap kejadian STK pada pekerja. Semakin lama 
masa kerja seseorang maka semakin lama terjadi gerakan berulang pada tangan secara terus-menerus dalam jangka waktu yang lama, sehingga menyebabkan peningkatan tekanan pada jaringan disekitar terowongan carpal (Mohammad, 2019).

Faktor risiko masa kerja berkontribusi terhadap risiko STK. Lamanya masa kerja yang dihabiskan dalam pengerahan tenaga secara terus menuerus dapat menjadi risiko yang lebih besar untuk STK (Burt et al., 2013). Lo, Chiu, Tu, Liu, and Yu (2019) juga melaporkan hal yang senada bahwa pekerja di industri manufaktur merupakan pekerjaan yang membutuhkan kekuatan tangan yang ekstra. Masa kerja yang lebih lama berakibat pada semakin besarnya keluhan STK yang terjadi pada pekerja.

\section{Risiko Keluhan Sindrom Terowongan Karpal Pada Pekerja Berdasarkan La ma Kerja}

Keluhan Sindrom Terowongan Karpal berhubungan dengan jenis pekerjaan yang membutuhkan aktivitas berulang pada tangan atau pergelangan tangan secara terus menerus ataupun pekerjaan yang menggunakan alat-alat yang menghasilkan getaran dalam waktu yang lama sehingga berdampak pada tangan atau pergelangan tangan (Chammas et al., 2014).

Berdasarkan tabel 3 diperoleh hasil responden dengan kategori lama kerja yang berisiko dan terkena STK sebanyak 72 responden (90\%). Hal ini disebabkan karena pekerjaan mengupas kepiting merupakan aktivitas yang menggunakan kombinasi antara kekuatan dan pengulangan gerakan pada jari-jari tangan selama $\geq 6$ jam perhari, sehingga berisiko mengalami keluhan Sindrom Terowongan Karpal (Chammas et al., 2014; Ghasemi-Rad et al., 2014; Newington et al., 2015).

Demikian halnya $2,5 \%$ responden yang memiliki lama kerja tidak berisiko tetapi menderita keluhan Sindrom Terowongan Karpal, hal ini disebabkan karena semakin lama waktu yang digunakan bekerja sebagai pengupas kepiting maka semakin panjang waktu yang digunakan mengerjakan pekerjaan yang melibatkan gerakan tangan, sehingga frekuensi gerakan tangan berulang dalam satu menit menjadi kecil. Hal ini sejalan dengan riset Setyawan (2017) pada pekerja 
pengepakan makanan bahwa lama kerja berhubungan terhadap kejadian Carpal Tunnel Syndrome. Pekerja pengepak makanan melakukan pekerjaan berulang dalam waktu yang lama meskipun dalam rentang waktu yang singkat.

\section{Risiko Keluhan Sindrom Terowongan Karpal Berdasarkan Gerakan Berulang.}

Aktivitas atau gerakan berulang adalah pekerjaan yang dilakukan secara terus-menerus sehingga berisiko mengalami keluhan otot, karena otot menerima tekanan akibat beban kerja secara terus-menerus tanpa memperoleh kesempatan untuk relaksasi Salah satu bentuk keluhan otot pada pengupas kepiting adalah keluhan Sindrom Terowongan Karpal (Devrimsel et al., 2014; Spahn et al., 2012)

Pada penelitian ini terdapat 74 responden $(80,6 \%)$ yang mengalami keluhan Sindrom Terowongan Karpal dengan melakukan pekerjaan/gerakan repetitive atau pengulangan $\geq 30$ gerakan/menit dan sebesar 20,0\% responden tidak berisiko mengalami Sindrom Terowongan Karpal dengan pekerjaan repetitif $<30$ gerakan/menit. Hal ini sejalan dengan riset yang dilakukan Bina Kurniawan et al tahun 2008, bahwa $67,5 \%$ pekerja yang melakukan gerakan berulang berisiko ( $\geq$ 30 gerakan/menit) mengalami Sindrom Terowongan Karpal.

$10 \%$ responden yang tidak melakukan gerakan berulang berisiko tetapi merasakan keluhan Sindrom Terowongan Karpal, hal ini disebabkan karena karyawan wanita tersebut telah terbiasa mengupas kepiting dengan menggunakan gerakan berulang pada area tangan dan jari-jarinya sehingga responden tidak merasakan lagi keluhan STK tersebut. Demikian halnya yang dikemukakan oleh Aboonq (2015) bahwa faktor gerakan berulang merupakan faktor terjadinya 73\% kasus Carpal Tunnel Syndrome(CTS) pada pekerja di industri pengolahan ikan.

Karyawan wanita memiliki risiko gangguan muskuloskeletal, karena kecenderungan pihak pemberi kerja memberikan pekerjaan yang mengharuskan pekerjaan tersebut dilakukan secara monoton dan berulang secara terus menerus dalam jangka waktu yang lama, serta Alat Pelindung Diri yang digunakan terkadang tidak sesuai dengan ukuran tubuh pekerja wanita (Merijanti, 2005 dalam Annisa, 2014). 
Namun ditemukan 5\% responden melakukan gerakan berulang berisiko tetapi tidak mengalami Sindrom Terowongan Karpal, hal ini disebabkan karena responden tersebut tidak melakukan aktivitas gerakan berulang melebihi 30 gerakan per menit.

\section{Gambaran Faktor Risiko Sindrom Terowongan Karpal Berdasarkan Pekerjaan Menggenggam.}

Terdapat 71,25\% responden melakukan pekerjaan menggenggam selama $\geq$ 6 jam/hari dan mengalami keluhan Sindrom Terowongan Karpal. Hal ini disebabkan karena pekerjaan mengupas kepiting dilakukan dengan menggenggam pisau sebagai alat bantu selama $\geq 6$ jam/hari dengan intensitas frekuensi repetitif yang tinggi dsecara terus menerus dengan dengan waktu yang lama (Setyowati et al., 2015). Sedangkan responden yang melakukan pekerjaan menggenggam kurang dari 6 jam perhari hanya 17 responden atau (21,25\%) yang mengalami keluhan STK.

\section{KESIMPULAN DAN IMPLIKASI}

Penelitian ini dapat disimpulkan sebagai berikut:

1. Sebanyak $74(92,5 \%)$ karyawan wanita di PT.X mengalami keluhan Sindrom Terowongan Karpal (STK)

2. Mayoritas karyawan wanita di PT.X yang berumur $\geq 35$ tahun mengalami keluhan STK sebesar 58,75\%,

3. Mayoritas karyawan wanita di PT.X dengan masa kerja $\geq 2$ tahun mengalami keluhan STK 56,25\%

4. Mayoritas karyawan wanita di PT.X dengan lama kerja $\geq 6$ jam/hari mengalami STK 90\%,

5. Mayoritas karyawan wanita di PT.X dengan gerakan berulang $\geq 30$ gerakan/menit mengalami keluhan STK sebesar 82,50\%, dan

6. Mayoritas karyawan wanita di PT.X dengan pekerjaan menggenggam $\geq 6$ jam / hari mengalami STK sebesar 71,25\%.

Adapun implikasinya diharapkan pihak PT.X memaksimalkan sosialisasi faktor risiko Sindrom Terowongan Karpal melalui pemberdayaan karyawan wanita (teman sebaya)pada unit kerja masing-masing. 


\section{REFERENSI}

Aboonq, M. S. (2015). Pathophysiology of carpal tunnel syndrome. Neurosciences (Riyadh),20(1),4-9.

Basuki, R., Jenie, M. N., \& Fikri, Z. (2015). Faktor Prediktor Carpal Tunnel Syndrome (CTS) pada Pengrajin Alat Tenun Bukan Mesin (ATBM). Jurnal Kedokteran Muhammadiyah Universitas Muhammadiyah Semarang, 4.

Burt, S., Deddens, J. A., Crombie, K., Jin, Y., Wurzelbacher, S., \& Ramsey, J. (2013). A prospective study of carpal tunnel syndrome: workplace and individual risk factors. Occup Environ Med, 70(8), 568-574. doi: 10.1136/oemed-2012101287

Chammas, M., Boretto, J., Burmann, L. M., Ramos, R. M., Dos Santos Neto, F. C., \& Silva, J. B. (2014). Carpal tunnel syndrome - Part I (anatomy, physiology, etiology and diagnosis). Rev Bras Ortop, 49(5), 429-436. doi: 10.1016/j.rboe.2014.08.001

Dale, A. M., Harris-Adamson, C., Rempel, D., Gerr, F., Hegmann, K., Silverstein, B., ... Evanoff, B. (2013). Prevalence and incidence of carpal tunnel syndrome in US working populations: pooled analysis of six prospective studies. Scand J Work Environ Health, 39(5), 495-505. doi: 10.5271/sjweh.3351

Devrimsel, G., Kirbas, S., Yildirim, M., Turkyilmaz, A. K., \& Sahin, N. (2014). Carpal tunnel syndrome in women working in tea agriculture. North Clin Istanb, 1(3), 132-136. doi: 10.14744/nci.2014.42714

Genova, A., Dix, O., Saefan, A., Thakur, M., \& Hassan, A. (2020). Carpal Tunnel Syndrome: A Review of Literature. Cureus, 12(3), e7333-e7333. doi: 10.7759/cureus.7333

Ghasemi-Rad, M., Nosair, E., Vegh, A., Mohammadi, A., Akkad, A., Lesha, E., ... Hasan, A. (2014). A handy review of carpal tunnel syndrome: From anatomy to diagnosis and treatment. World J Radiol, 6(6), 284-300. doi: 10.4329/wjr.v6.i6.284

Ghasemi, F., Gholamizadeh, K., Rahmani, R., \& Doosti-Irani, A. (2020). Prevalence and severity of carpal tunnel syndrome symptoms among Iranian butchers and their association with occupational risk factors: Implications for ergonomic interventions. Work, 66(4), 817-825. doi: 10.3233/wor-203227

Guan, W., Lao, J., Gu, Y., Zhao, X., Rui, J., \& Gao, K. (2018). Case-control study on individual risk factors of carpal tunnel syndrome. Exp Ther Med, 15(3), 2761-2766. doi: 10.3892/etm.2018.5817

Lo, V. E., Chiu, Y. C., Tu, H. H., Liu, C. W., \& Yu, C. Y. (2019). A Pilot Study of Five Types of Maximum Hand Strength among Manufacturing Industry Workers in Taiwan. Int J Environ Res Public Health, 16(23). doi: 10.3390/ijerph16234742

Luckhaupt, S. E., Dahlhamer, J. M., Ward, B. W., Sweeney, M. H., Sestito, J. P., \& Calvert, G. M. (2013). Prevalence and work-relatedness of carpal tunnel 
syndrome in the working population, United States, 2010 National Health Interview Survey. Am J Ind Med, 56(6), 615-624. doi: 10.1002/ajim.22048

Mallapiang, F., \& Wahyudi, A. A. (2015). Gambaran Faktor Pekerjaan dengan Kejadian Carpal Tunnel Syndrome ( CTS ) pada Pengrajin Batu Tatakan di Desa Lempang Kec . Tanete Riaja Kabupaten Barru Tahun 2015. Public Health Science Journal, 6(2), 7.

Mansfield, M., Thacker, M., \& Sandford, F. (2018). Psychosocial Risk Factors and the Association With Carpal Tunnel Syndrome: A Systematic Review. Hand (N Y), 13(5), 501-508. doi: 10.1177/1558944717736398

Mohammad, W. S. (2019). Work-related risk factors for Carpal Tunnel Syndrome among Majmaah University female touchscreen users. PakJ Med Sci, 35(5), 1221-1226. doi: 10.12669/pjms.35.5.683

Musolin, K., Ramsey, J. G., Wassell, J. T., \& Hard, D. L. (2014). Prevalence of carpal tunnel syndrome among employees at a poultry processing plant. Appl Ergon, 45(6), 1377-1383. doi: 10.1016/j.apergo.2014.03.005

Musolin, K. M., \& Ramsey, J. G. (2017). Carpal tunnel syndrome prevalence: an evaluation of workers at a raw poultry processing plant. Int J Occup Environ Health, 23(4), 282-290. doi: 10.1080/10773525.2018.1474420

Newington, L., Harris, E. C., \& Walker-Bone, K. (2015). Carpal tunnel syndrome and work. Best Pract Res Clin Rheumatol, 29(3), 440-453. doi: 10.1016/j.berh.2015.04.026

NIOSH. (2014). Health Hazard Evaluation Report : Evaluation Of Musculoskeletal Disorders And Traumatic Injuries Among Employees At A Poultry Processing Plant.

Palmer, K. T. (2011). Carpal tunnel syndrome: the role of occupational factors. Best Pract Res Clin Rheumatol, 25(1), 15-29. doi: 10.1016/j.berh.2011.01.014

Roquelaure, Y., Ha, C., Pelier-Cady, M. C., Nicolas, G., Descatha, A., Leclerc, A., . . Imbernon, E. (2008). Work increases the incidence of carpal tunnel syndrome in the general population. Muscle Nerve, 37(4), 477-482. doi: 10.1002/mus.20952

Setyawan, H. (2017). Risk Factors of Carpal Tunnel Syndrome in Food-Packing Workers Karanganyar. Jurnal Kesehatan Masyarakat Nasional, 11(3).

Setyowati, D. L., Dwijayanti, D., \& Sultan, M. (2015). Related Factors of Carpal Tunnel Syndrome (CTS) among Onion Skin Peeler Worker at Segiri Samarinda, East Kalimantan. Kes Mas Jurnal Fakultas Kesehatan Masyarakat, $9(2)$.

Sosan, I. (2013). PERAN GANDA IBU RUMAH TANGGA YANG BEKERJA SEBAGAI TUKANG AMPLAS KERAJINAN UKIR KAYU. Jurnal Komunitas, 2. doi: 10.15294/komunitas.v2i2.2279

Spahn, G., Wollny, J., Hartmann, B., Schiele, R., \& Hofmann, G. O. (2012).

[Metaanalysis for the evaluation of risk factors for carpal tunnel syndrome 
(CTS) Part II. Occupational risk factors]. Z Orthop Unfall, 150(5), 516-524. doi: 10.1055/s-0032-1315346

Triana, A., \& Krisnani, H. (2018). Peran Ganda Ibu Rumah Tangga Pekerja K31 UNPAD Dalam Rangka Menunjang Perekonomian Keluarga Prosiding Penelitian \& Pengabdian Kepada Masyarakat, 5(2), 10.

Yazdanpanah, P., Aramesh, S., Mousavizadeh, A., Ghaffari, P., Khosravi, Z., \& Khademi, A. (2012). Prevalence and severity of carpal tunnel syndrome in women. Iranian journal of public health, 41(2), 105-110. 